\title{
Household Decision-making about Delivery in Health Facilities: Evidence from Tanzania
}

\author{
E.J. Danforth', M.E. Kruk², P.C. Rockers ${ }^{3}$, G. Mbaruku', and S. Galea ${ }^{3}$
}

'Department of Anthropology, University of South Florida, 4202 E. Fowler Avenue, Tampa, Florida, 33620, USA, ${ }^{2}$ Department of
Health Management and Policy, University of Michigan School of Public Health, I09 Observatory Road, SPH II M3I66, Ann Arbor,
MI, 48I09, USA and Averting Maternal Death and Disability Programme Heilbrunn Department of Population and Family Health,
Mailman School of Public Health, Columbia University, 60 Haven Avenue, Room B-320, New York, NY I0032, USA, ${ }^{3}$ Department
of Epidemiology, University of Michigan School of Public Health, I09 Observatory Road, SPH II M3I66, Ann Arbor, MI, 48I09,
USA, and ${ }^{4}$ Ifakara Health Institute and Averting Maternal Death and Disability, Mikocheni, PO Box 78373, Dar-es-salaam, Tanzania

\section{ABSTRACT}

This study investigated how partners' perceptions of the healthcare system influence decisions about delivery-location in low-resource settings. A multistage population-representative sample was used in Kasulu district, Tanzania, to identify women who had given birth in the last five years and their partners. Of 826 couples in analysis, 506 (61.3\%) of the women delivered in the home. In multivariate analysis, factors associated with delivery in a health facility were agreement of partners on the importance of delivering in a health facility and agreement that skills of doctors are better than those of traditional birth attendants. When partners disagreed, the opinion of the woman was more influential in determining delivery-location. Agreement of partners regarding perceptions about the healthcare system appeared to be an important driver of decisions about delivery-location. These findings suggest that both partners should be included in the decision-making process regarding delivery to raise rates of delivery at facility.

Key words: Delivery; Healthcare; Health services; Maternal mortality; Partner's influence; Tanzania

\section{INTRODUCTION}

Maternal mortality is the leading cause of death among women of reproductive age in developing countries (1). Although great gains have been made in the past two decades in reducing childhood morbidity and mortality and in improving reproductive health in general, significant reductions in maternal mortality have been elusive (2). Technical improvements are essential to improve birth outcomes in many settings; however, more distal influences, such as the larger sociocultural environment, have important impacts on the decision to seek professional care (3).

There is now consensus that increasing rates of delivery with a skilled attendant (doctor, nurse, or midwife), ideally in a well-equipped facility, are es-

Correspondence and reprint requests should be addressed to:

Dr. M.E. Kruk

Department of Health Management and Policy

University of Michigan School of Public Health

109 Observatory Road, SPH II M3166

Ann Arbor, MI, 48109

USA

Email:mkruk@umich.edu sential to reduce maternal mortality globally $(4,5)$. While technical biomedical improvements are important, attention to larger, socially-shaped aspects, such as access, use, and quality, is essential to reducing maternal and neonatal deaths in developing countries. Women are not necessarily autonomous agents in decisions regarding childbirth, and influence of partners on reproductive health outcomes has been shown to be both direct and indirect-biological and social $(6,7)$. In low-resource settings such as Tanzania, strategic decisions may have to be made regarding delivery in a health facility, which is more expensive and less convenient than delivery in the home, and it is likely that these decisions are influenced by partners and other household members.

Power and influence within the household have been repeatedly shown to affect reproductive health outcomes, such as delivery-location; relative power rather than absolute power has shown to be most predictive (8-10). At the individual level, social and demographic factors, such as wealth and education, are important in the power relationships between partners and more directly in determining use of health services (11-13). At the household level, 
partner communication and type of relationship also influence the use and perceptions of services. Finally, social, political and economic conditions of the community are the context in which interactions of partners and making decision are based on (10). Understanding how partners influence delivery-location is essential in increasing rates of skilled birth attendance in Tanzania where reducing maternal mortality is a key government priority (14). This study seeks to investigate how perceptions of women and their partners about the health system and how agreement and disagreement in those perceptions influence the decision to deliver in a health facility.

\section{MATERIALS AND METHODS}

\section{Study site}

The United Republic of Tanzania is situated along the coast of the Indian Ocean in Africa's Great Lakes region. The country with a population of 34 million has over 126 distinct ethnic groups. Most rural people in Tanzania practise subsistence agriculture. Seventy-one percent of the population works in the agricultural sector, and almost $80 \%$ of women in this sector are unpaid (15). The most recent estimate of the maternal mortality ratio (MMR) is 950 per 100,000 livebirths. In 2005 , only $47 \%$ of deliveries overall and only 39\% of rural deliveries took place in a health facility (15).

The study was conducted in Kasulu district (population 630,000), situated along the Lake Tanganyika and the Burundi border in western Tanzania. The district is primarily rural, with one main townKasulu town (population 33,000). As in the rest of Tanzania, most people in the district are subsistence farmers with limited integration into the market economy. The main ethnic affiliation is Muha, and most are bilingual in the Muha language Kiha and the national language Kiswahili. An official map of Kasulu district with location of all healthcare facilities was obtained and validated through discussions with local collaborators. Healthcare services are provided at the 70 functioning health facilities of the district (48 government dispensaries, six government health centres, one government hospital, and 15 mission facilities). The main government hospital is centrally located in the region, in Kasulu town.

\section{Sampling}

A two-stage representative cluster-sampling strategy was used for selecting rural households for participation in the study. The inclusion criteria limited participants to women aged over 18 years, with a delivery within the previous five years, and their partners aged over 18 years. 'Partner' was defined by the woman interviewed and included both married and unmarried partners. First, 50 villages, excluding Kasulu town, were selected within the district, with probability proportional to village size. One kitongoji (sub-village) was randomly selected in each village, and 35 households were randomly selected from a household list kept by the kitongoji leader. Approval for research on human subjects for the study was obtained from the National Institute for Medical Research in Tanzania and from the Institutional Review Board at the University of Michigan. Written consent was obtained from all the respondents.

\section{Instrument and survey fielding}

Data for this study were collected through a household survey. The survey instrument for men and women asked about previous illness and injury, knowledge and perception of the local healthcare system, and barriers to healthcare-use. Additionally, the questionnaire for women asked about household composition, characteristics and assets (indicators of socioeconomic status/wealth), and history of childbirth. The questionnaire and consent documents were developed in English and then translated into Swahili and back-translated to ensure accuracy. Trained interviewers administered the survey through face-to-face interviews conducted in Swahili (or Kiha when necessary). Interviews lasted for approximately 30 minutes. Interviewers were grouped into two teams, with each team visiting one village each day. A supervisor monitored each team, checked the quality of all completed interviews, and observed two or more interviews per day. The questionnaire was administered from June to mid-July 2007.

\section{Statistical analysis}

Univariate statistics were calculated for the demographic and healthcare-related variables. A relative index of socioeconomic status was constructed using principal component analysis of household asset information (16). Bivariate associations with delivery in the facility status were calculated for a range of variables, including demographics and perceptions of households about the healthcare system. A multivariate logistic regression model was used for estimating associations between potential determinants and delivery in the facility status. In addition to the final model, two models were constructed to investigate the association of each perception variable, independent of the other. Models were also 
constructed to investigate demographic determinants of the perception variables to assess potential confounding. All statistical analyses were adjusted for cluster design in the survey and were carried out with the SAS-Callable SUDAAN software (version 9.0.3) (17).

\section{RESULTS}

Of 1,322 eligible women, 1,212 women (91\%) and 899 male partners completed interviews. However, one woman did not provide her delivery-location, 54 men were interviewed who did not have female partners included in the study, and 18 female partners delivered before arrival at a health facility. In total, 826 male-female pairs provided sufficient information for both partners and were included in this analysis. Table 1 describes the demographic characteristics of the study population. The average age for men in the sample was 36.4 years (standard deviation $[\mathrm{SD}]=9.7$ ), and for women it was 30.1 years $(\mathrm{SD}=7.2)$. Approximately two-thirds $(66 \%)$ of the men and $60 \%$ of the women had completed primary school (seven years in Tanzania). Most respondents were ethnically Muha (98.2\%), married (99.3\%), and involved in farming or fishing (men 93.5\%; women 98.5\%). Most respondents were Christians (men 88\%; women 90.6\%), although a significant minority were Muslims (men 9.7\%; women $7.7 \%$ ). High rates of fertility were present in this population as $44.6 \%$ of the couples had $2-4$ living children, and $41.5 \%$ had five or more. Approximately $75 \%$ of the population lived in a village with a health facility. However, delivery in the home was more common than using a health facility, with $61.3 \%$ of the women delivering their last child in the home.

Bivariate associations between the potential determinants and the place of delivery are shown in Table 2. Delivery in the facility (vs delivery in the home) was associated with $\leq 2$ living children in the household, having a health facility located within the village, both partners agreeing that delivery in a facility was very important, and women perceiving skills of government doctors and nurses to be higher than skills of traditional birth attendants (TBAs), regardless of the perceptions of man about those skills. It is worth noting that disagreement on the importance of delivery in the facility and the skills of doctors and nurses was relatively common, with $27.9 \%$ of the couples expressing disagreement on the former and $26.3 \%$ of the couples disagreeing on the latter.
The final model used for multivariate analysis (Table 3) identified several significant predictors of delivery in the facility. Factors associated with delivery in the facility were $<2$ living children, both partners agreeing that delivery in the facility was very important, and women perceiving skills of government service providers to be greater than skills of TBAs, regardless of the perception of their male partners. Results from two separate multivariate models, each with a single perception variable, showed no significant differences in associations, suggesting that there was no collinearity between the variables. Additionally, to explore potential confounding between the demographic variables and the health system perception variables, we estimated a multivariate model with disagreement (versus agreement) as the dependent variable and the same set of demographic variables as in the models in Table 3 . The only significant variable that raised the odds of disagreement about the importance of delivery in the facility was having two or more children. None of the demographic variables was significant in a similar model with disagreement about skills of service providers as the dependent variable.

\section{DISCUSSION}

In this study, we found that, among couples with a recent delivery in western rural Tanzania, agreement of partners regarding the importance of delivery in the facility was associated with a higher likelihood of women delivering in a health facility. Specifically, when both partners rated skills of government doctors and nurses as higher than that of TBAs, the woman was twice as likely to deliver at a health facility than in the home, controlling for other confounders. These findings highlight the importance of considering cultural gender dynamics within the household in the understanding of decision-making within households and in planning reproductive health outreach to increase rates of delivery in health facilities. Agreement of partners and male involvement are important in various aspects of reproductive health, including abortion, family planning, sexually transmitted diseases, and breastfeeding (18-27). Spousal communication about reproductive health is important in decisions about accessing maternal health services in both developed and developing countries $(7,9,27-31)$.

Examples of the importance of spousal communication and agreement on healthcare-use come from a number of developing countries. Work from 
Table 1. Demographic characteristics of a population-based sample of partners from Kasulu district, western Tanzania, $2007(\mathrm{n}=826)$

\begin{tabular}{|c|c|c|}
\hline Characteristics & No. & $\%$ \\
\hline \multicolumn{3}{|l|}{ Male demographics } \\
\hline Age, mean (SD) & 36.4 & 9.7 \\
\hline \multicolumn{3}{|l|}{ Education } \\
\hline No schooling & 122 & 14.8 \\
\hline Some primary & 143 & 17.3 \\
\hline Completed primary & 545 & 66.0 \\
\hline Some secondary or more & 16 & 1.9 \\
\hline Occupation: farming or fishing & 772 & 93.5 \\
\hline Ethnicity Muha & 811 & 98.2 \\
\hline \multicolumn{3}{|l|}{ Religion } \\
\hline Christian & 727 & 88.0 \\
\hline Muslim & 80 & 9.7 \\
\hline \multicolumn{3}{|l|}{ Female demographics } \\
\hline Age, mean (SD) & 30.1 & 7.2 \\
\hline \multicolumn{3}{|l|}{ Education } \\
\hline No schooling & 229 & 27.7 \\
\hline Some primary & 90 & 10.9 \\
\hline Completed primary & 505 & 61.1 \\
\hline Some secondary or more & 2 & 0.2 \\
\hline Occupation: farming or fishing & 814 & 98.5 \\
\hline Ethnicity Muha & 812 & 98.3 \\
\hline \multicolumn{3}{|l|}{ Religion } \\
\hline Christian & 748 & 90.6 \\
\hline Muslim & 64 & 7.7 \\
\hline \multicolumn{3}{|l|}{ Partner demographics } \\
\hline Currently married & 820 & 99.3 \\
\hline \multicolumn{3}{|l|}{ Number of living children } \\
\hline $0-1$ & 108 & 13.1 \\
\hline $2-4$ & 368 & 44.6 \\
\hline 5 or more & 343 & 41.5 \\
\hline \multicolumn{3}{|l|}{$\begin{array}{l}\text { Distance }(\mathrm{km}) \text { to the nearest } \\
\text { health facility }\end{array}$} \\
\hline In village & 626 & 75.8 \\
\hline $0.1-4.9$ & 52 & 6.3 \\
\hline$\geq 5$ & 148 & 17.9 \\
\hline \multicolumn{3}{|l|}{ Location of delivery } \\
\hline Home & 506 & 61.3 \\
\hline Government dispensary & 78 & 9.4 \\
\hline Government health centre & 39 & 4.7 \\
\hline Government hospital & 53 & 6.4 \\
\hline Mission health facility & 150 & 18.2 \\
\hline $\mathrm{SD}=$ Standard deviation & & \\
\hline
\end{tabular}

Nepal showed that, when women discussed family planning with their partners, they were more likely to receive antenatal and delivery care (25). A randomized controlled trial in Nepal, testing the impact of involving husbands in antenatal health education, found that educating both partners yielded a greater impact on maternal health behaviours than educating women alone (27). Results of demographic and health surveys in Ghana also showed that data from both spouses led to significantly better models for predicting contraceptive-use than variables from either spouse alone (32). The inclusion of men in reproductive health education in Mayan communities in Guatemala has also been shown to be helpful in enhancing male support of reproductive healthcare in the community (33). Other studies confirm that excluding men from a reproductive health programme may limit its impact $(7,34,35)$. This finding is important to the Tanzanian context as lack of transport, quality of poor-roads, and responsibilities of the household make delivery at health facilities difficult without prior joint planning.

We found that more than one in four couples disagreed about the importance of delivery in the facility and the relative skills of doctors and nurses versus TBAs. However, when the couple disagreed, the opinion of wife was more important in predicting delivery-location. Perceptions of women that delivery in the facility was not important were associated with lower likelihood of delivery in the facility than was a similar perception among men. When the wife rated skills of doctors and nurses higher than those of TBAs, she was more than twice as likely to deliver in a health facility. On the other hand, in the context of disagreement about skills of service providers, the beliefs of husbands did not influence the decision on delivery. This is consistent with the literature which demonstrates considerable discordance in attitudes and desires of partners regarding family size, family planning, and reproductive health in developing countries (28).

Our finding that views of women tend to hold sway in making decision about the use of maternal health services is supported by work by Bankole and Singh who found that, across six developing countries, when disagreement of partners existed, preferences of women for contraceptive-use had a stronger influence on actual practices than men (36). Several studies have investigated power in making decision among American couples and found that variables associated with the wife are more important than those associated with the husband in determining reproductive health decisions in American contexts (28). 
Table 2. Bivariate regression results predicting likelihood of facility delivery for population-based sample from Kasulu district, western Tanzania, 2007 ( $n=826)$

\begin{tabular}{|c|c|c|c|c|c|c|}
\hline \multirow[t]{2}{*}{ Variable } & \multicolumn{2}{|c|}{$\begin{array}{l}\text { Home delivery } \\
\qquad(\mathrm{n}=506)\end{array}$} & \multicolumn{2}{|c|}{$\begin{array}{l}\text { Facility delivery } \\
\qquad(\mathrm{n}=320)\end{array}$} & \multirow[t]{2}{*}{ OR } & \multirow[t]{2}{*}{$95 \% \mathrm{CI}$} \\
\hline & No. & $\%$ & No. & $\%$ & & \\
\hline \multicolumn{7}{|l|}{ Demographics } \\
\hline \multicolumn{7}{|l|}{ Age (years) of husband } \\
\hline$<35$ & 231 & 45.7 & 164 & 51.3 & Ref & \\
\hline$\geq 35$ & 271 & 53.6 & 154 & 48.1 & 0.80 & $0.58-1.10$ \\
\hline \multicolumn{7}{|l|}{ Age (years) of wife } \\
\hline$<35$ & 358 & 70.8 & 235 & 73.4 & Ref & \\
\hline$\geq 35$ & 148 & 29.2 & 85 & 26.6 & 0.87 & $0.64-1.19$ \\
\hline \multicolumn{7}{|l|}{ Wealth status } \\
\hline $1^{\text {st }}$ quintile & 83 & 16.4 & 56 & 17.5 & Ref & \\
\hline $5^{\text {th }}$ quintile & 99 & 19.6 & 61 & 19.1 & 0.91 & $0.49-1.71$ \\
\hline \multicolumn{7}{|l|}{ Education of husband } \\
\hline No schooling & 79 & 15.6 & 46 & 14.4 & Ref & \\
\hline Some schooling & 427 & 84.4 & 274 & $85.6)$ & 1.10 & $0.65-1.87$ \\
\hline \multicolumn{7}{|l|}{ Number of living children } \\
\hline $0-1$ & 36 & 7.1 & 72 & 22.5 & Ref & \\
\hline $2-4$ & 240 & 47.4 & 128 & 40.0 & $0.27^{\star \star \star}$ & $0.16-0.44$ \\
\hline 5 or more & 227 & 44.9 & 116 & 36.3 & $0.26^{\star * *}$ & $0.15-0.44$ \\
\hline \multicolumn{7}{|l|}{ Location of the nearest health facility } \\
\hline In village & 357 & 70.6 & 269 & 84.1 & Ref & \\
\hline Outside village & 149 & 29.4 & 51 & 15.9 & $0.45^{\star * *}$ & $0.22-0.92$ \\
\hline \multicolumn{7}{|l|}{ Perceptions of the healthcare system } \\
\hline \multicolumn{7}{|l|}{$\begin{array}{l}\text { Partners' agreement regarding the } \\
\text { importance of delivering in a facility }\end{array}$} \\
\hline Both report very important & 291 & 57.5 & 245 & 76.6 & Ref & \\
\hline $\begin{array}{l}\text { Wife reports very important/husband } \\
\text { reports less than very important }\end{array}$ & 51 & 10.1 & 22 & 6.9 & $0.51^{\star \star \star}$ & $0.31-0.84$ \\
\hline $\begin{array}{l}\text { Husband reports very important/ } \\
\text { wife reports less than very important }\end{array}$ & 90 & 17.8 & 21 & 6.6 & $0.28^{\star \star \star}$ & $0.17-0.45$ \\
\hline Both report less than very important & 70 & 13.8 & 32 & 10.0 & $0.54^{\star \star \star}$ & $0.33-0.90$ \\
\hline \multicolumn{7}{|l|}{$\begin{array}{l}\text { Perceptions of partners about } \\
\text { skills of doctors versus skills of TBAs }\end{array}$} \\
\hline Both report skills same or lower & 89 & 17.6 & 31 & 9.7 & Ref & \\
\hline $\begin{array}{l}\text { Wife reports higher skills/husband } \\
\text { same or lower }\end{array}$ & 56 & 11.1 & 42 & 13.1 & $2.15^{\star * *}$ & $1.24-3.73$ \\
\hline $\begin{array}{l}\text { Husband reports higher skills/wife } \\
\text { same or lower }\end{array}$ & 77 & 15.2 & 36 & 11.3 & 1.34 & $0.71-2.55$ \\
\hline Both report higher & 252 & 49.8 & 189 & 59.1 & $2.15^{\star * \star}$ & $1.32-3.52$ \\
\hline
\end{tabular}

However, such findings are not universal, and sociocultural factors appear to play an important role in determining the relative influence of each partner on the decision on delivery. Other research on making decision about reproductive health and disagreement of partners has shown that lack of support by men can inhibit access of women to family-planning methods and maternal healthcare (35). This is especially true when significant costs are associated with the care as men frequently hold 


\begin{tabular}{|c|c|c|}
\hline Variable & OR & $95 \% \mathrm{CI}$ \\
\hline \multicolumn{3}{|l|}{ Demographics } \\
\hline \multicolumn{3}{|l|}{ Age (years) of wife } \\
\hline$<35$ & Ref & \\
\hline$\geq 35$ & 1.05 & $0.75-1.48$ \\
\hline \multicolumn{3}{|l|}{ Wealth status } \\
\hline $1^{\text {st }}$ quintile & Ref & \\
\hline $5^{\text {th }}$ quintile & 0.88 & $0.45-1.70$ \\
\hline \multicolumn{3}{|l|}{ Education of husband } \\
\hline No schooling & Ref & \\
\hline Some schooling & 1.06 & $0.63-1.79$ \\
\hline \multicolumn{3}{|l|}{ Number of living children } \\
\hline $0-1$ & Ref & \\
\hline 2 or more & $0.25^{\star \star *}$ & $0.15-0.43$ \\
\hline \multicolumn{3}{|l|}{ Location of the nearest health facility } \\
\hline In village of residence & Ref & \\
\hline Outside village of residence & $0.54^{*}$ & $0.26-1.12$ \\
\hline \multicolumn{3}{|l|}{ Perceptions of the healthcare system } \\
\hline \multicolumn{3}{|l|}{ Partners' agreement regarding the importance of delivering in a facility } \\
\hline Both report very important & Ref & \\
\hline Wife reports very important/husband reports less than very important & $0.61^{* *}$ & 0.38-0.99 \\
\hline Husband reports very important/wife reports less than very important & $0.32^{\star \star \star}$ & $0.19-0.53$ \\
\hline Both report less than very important & 0.66 & $0.37-1.16$ \\
\hline \multicolumn{3}{|l|}{ Perceptions of partners about skills of doctors versus skills of TBAs } \\
\hline Both report skills same or lower & Ref & \\
\hline Wife reports higher skills/husband same or lower & $2.50^{\star \star \star}$ & $1.51-4.15$ \\
\hline Husband reports higher skills/wife same or lower & 1.50 & $0.78-2.90$ \\
\hline Both report higher & $2.22^{* \star *}$ & $1.38-3.58$ \\
\hline
\end{tabular}

economic power within the households. For example, beliefs of men about breastfeeding predicted both intentions and actual behaviour of women to a greater extent than women's own beliefs on breastfeeding and intentions in a study in Canada. Additionally, this study found that women changed the duration of their breastfeeding in the direction their partner indicated prenatally they should (24). A study in Nepal found that women who were younger and poorer and had more traditional attitudes about gender were less able to have final decision-making power, were less likely to access reproductive healthcare, and received less instrumental support during pregnancy and after childbirth (35). In Indonesia, economic and social factors influenced the distribution of bargaining power between partners, and that ability of women to making the final decisions was dependent on relative education, social status of the family, and education of father compared to her father-in-law's (9).

One limitation of our study is that the survey did not include measures of power distribution within the household. Factors, such as control of money, food, and other resources, have been shown in other studies to be important in determining the influence of partners, in reproductive health. Additionally, although our focus was on making decision within couples, inclusion of other household members, such as mothers and mothers-in-law, may have provided more insights into the intrahousehold distribution of power and how deliv- 
ery-location is influenced by the presence of other adults in the household.

In developing approaches to improving partner communication and agreement about use of lifesaving maternal health services, it is important to consider that the extent and nature of partner communication about reproductive healthcare is determined by a myriad of sociocultural factors. A study in Uganda found that communication rates varied widely by reproductive health topic and that significant bargaining and cost-benefit analysis occurred in these interactions. Communication was also frequently non-verbal and used sociocultural pathways, such as hints, discussions with others, and behaviour to convey messages (29). In making decision relating to fertility, larger cultural preferences have been shown to influence the number of children a family has when there is disagreement between partners regarding 'ideal' family size (37). Additionally, communication models and strategies may be very different from Western models of discussion and negotiation, and quantitatively more communication may not lead to more agreement with regard to reproductive health (29). However, there is evidence that the inclusion of men in reproductive health strategies and education can be successful in improving women's use of family-planning and other health services. A programme in Ethiopia showed that education of men in modern contraceptive methods increased the use of such methods by wives over a 12-month period (21). This study also illustrated a lag between initial education and behaviour change, indicating that repeated or ongoing education and awareness strategies may be more beneficial than one-time events.

The present study has several implications for future research and action aimed at increasing the use of skilled obstetric care. In particular, future studies should consider the distribution of intra-household power and the role of partner communication and agreement in making decision about the place of delivery. This is a complex issue that requires careful qualitative assessment before implementing programming. One potential direction is for the health system to more systematically involve men, from family-planning education to antenatal care visits to delivery and postpartum care. Including men more consistently and meaningfully in decision-making about the use of essential reproductive healthcare has the potential to contribute to reducing maternal and neonatal mortality. The 1994 International
Conference on Development and Population highlighted the need for the inclusion of men in reproductive health $(38,39)$. Our findings taken together with those from studies in other parts of the developing world should spur health planners to develop health-system and health-education strategies to promote maternal and neonatal survival that are inclusive of both sexes.

\section{ACKNOWLEDGEMENTS}

The authors thank Dr. Calist Nzabuhakwa and Molly Moran for their capable supervision of the fieldwork for the study and Kat Hartman for her assistance in creating the graphics for the choice cards.

\section{REFERENCES}

1. Freedman L, Wirth M, Waldman R, Chowdhury M, Rosenfield A. Background paper of the Millenium Project Task Force on child health and maternal health. New York, NY: United Nations, 2003. 79 p.

2. Ronsmans C, Graham WJ; Lancet Maternal Survival Series steering group. Maternal mortality: who, when, where, and why. Lancet 2006;368:1189-200.

3. Kleinman A, Eisenberg L, Good B. Culture, illness, and care: clinical lessons from anthropologic and cross-cultural research. Focus 2006;4:140-9.

4. Koblinsky M, Matthews Z, Hussein J, Mavalankar D, Mridha MK, Anwar I et al. Going to scale with professional skilled care. Lancet 2006;368:1377-86.

5. World Health Organization. World health report 2005: make every mother and child count. Geneva: World Health Organization, 2005. 243 p.

6. Dudgeon MR, Inhorn MC. Men's influences on women's reproductive health: medical anthropological perspectives. Soc Sci Med 2004;59:1379-95.

7. Wegner MN, Landry E, Wilkinson D, Tzanis J. Men as partners in reproductive health: from issues to action. Int Fam Plan Perspect 1998;24:38-42.

8. Allendorf K. Couples' reports of women's autonomy and health-care use in Nepal. Stud Fam Plann 2007;38:35-46.

9. Beegle K, Frankenberg E, Thomas D. Bargaining power within couples and use of prenatal and delivery care in Indonesia. Stud Fam Plann 2001;32:130-46.

10. Blanc AK. The effect of power in sexual relationships on sexual and reproductive health: an examination of the evidence. Stud Fam Plann 2001;32:189-213.

11. Donnay F. Maternal survival in developing countries: what has been done, what can be achieved in the next decade. Int J Gynaecol Obstet 2000;70:89-97. 
12. Onah HE, Ikeako LC, Iloabachie GC. Factors associated with the use of maternity services in Enugu, southeastern Nigeria. Soc Sci Med 2006;63:1870-8.

13. Yanagisawa S, Oum S, Wakai S. Determinants of skilled birth attendance in rural Cambodia. Trop Med Int Health 2006;11:238-51.

14. Tanzania. Ministry of Health. Tanzania National Health Policy. Dar es Salaam: Ministry of Health, United Republic of Tanzania, 2003. 37 p.

15. National Bureau of Statistics. Tanzania demographic and health survey 2004-2005. Dar es Salaam: National Bureau of Statistics, 2005. 381 p.

16. Filmer D, Pritchett LH. Estimating wealth effects without expenditure data-or tears: an application to educational enrollments in states of India. Demography 2001;38:115-32.

17. Research Triangle Institute. SUDAAN. Research Triangel Park, NC: Research Triangle Institute, 2005.

18. Kroelinger CD, Oths KS. Partner support and pregnancy wantedness. Birth 2000;27:112-9.

19. Farquhar C, Kiarie JN, Richardson BA, Kabura MN, John FN, Nduati RW et al. Antenatal couple counseling increases uptake of interventions to prevent HIV-1 transmission. J Acquir Immune Defic Syndr 2004;37:1620-6.

20. Wang CC, Vittinghoff E, Hua LS, Yun WH, Rong ZM. Reducing pregnancy and induced abortion rates in China: family planning with husband participation. Am J Pub Health 1998;88:646-8.

21. Terefe A, Larson CP. Modern contraception use in Ethiopia: does involving husbands make a difference? Am J Public Health 1993;83:1567-71.

22. Sharma M, Petosa R. Impact of expectant fathers in breast-feeding decisions. J Am Diet Assoc 1997; 97:1311-3.

23. Kiarie JN, Richardson BA, Mbori-Ngacha D, Nduati RW, John-Stewart GC. Infant feeding practices of women in a perinatal HIV-1 prevention study in Nairobi, Kenya. J Acquir Immune Defic Syndr 2004;35:7581.

24. Rempel LA, Rempel JK. Partner influence on health behaviour decision- making: increasing breastfeeding duration. J Soc Pers Relat 2004;21:92-111.

25. Furuta M, Salway S. Women's position within the household as a determinant of maternal health care use in Nepal. Int Fam Plan Perspect 2006;32:17-27.

26. Mullany BC. Barriers to and attitudes towards promoting husbands' involvement in maternal health in Katmandu, Nepal. Soc Sci Med 2006;62:2798-809.
27. Mullany BC, Becker S, Hindin MJ. The impact of including husbands in antenatal health education services on maternal health practises in urban Nepal: results from a randomized controlled trial. Health Educ Res 2007;22:166-76.

28. Becker S. Couples and reproductive health: a review of couple studies. Stud Fam Plann 1996;27:291-306.

29. Blanc AK, Wolff B, Gage AJ, Ezeh AC, Neema S, Ssekamatte-Ssebuliba J. Negotiating reproductive outcomes in Uganda. Calverton, MD: Macro International, 1996. $215 \mathrm{p}$.

30. Dodoo FN. Men matter: additive and interactive gendered preferences and reproductive behavior in Kenya. Demography 1998;35:229-42.

31. Glei DA, Goldman N, Rodríguez G. Utilization of care during pregnancy in rural Guatemala: does obstetrical need matter? Soc Sci Med 2003;57:2447-63.

32. Ezeh AC. The influence of spouses over each other's contraceptive attitudes in Ghana. Stud Fam Plann 1993;24:163-74.

33. SchooleyJ, Mundt C, Wagner P, Fullerton J, O'Donnell $\mathrm{M}$. Factors influencing health care-seeking behaviours among Mayan women in Guatemala. Midwifery 2007;27:411-21.

34. Bloom SS, Wypij D, Das Gupta M. Dimensions of women's autonomy and the influence on maternal health care utilization in a north Indian city. Demography 2001;38:67-78.

35. Mullany BC, Hindin MJ, Becker S. Can women's autonomy impede male involvement in pregnancy health in Katmandu, Nepal? Soc SciMed 2005;61:19932006.

36. Bankole A, Singh S. Couples' fertility and contraceptive decision-making in developing countries: hearing the man's voice. Int Fam Plan Perspect 1998;24:1524.

37. Voas D. Conflicting preferences: a reason fertility tends to be too high or too low. Popul Dev Rev 2003;29:627-46.

38. Greene ME, Biddlecom AE. Absent and problematic men: demographic accounts of male reproductive roles. Popul Dev Rev 2000;26:81-115.

39. United Nations Population Fund. Report of the International Conference on Population and Development, Cairo, 5-13 September 1994. New York, NY: United Nations Population Fund, 1995. 193 p. 